\title{
Reduced Expression of FADS1 Predicts Worse Prognosis in Non-Small-Cell Lung Cancer
}

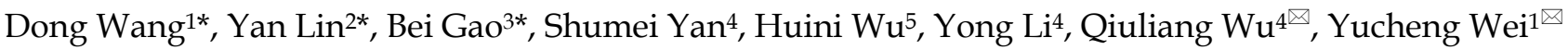 \\ 1. Department of Thoracic Surgery, Affiliated Hospital of Qingdao University, Qingdao 266000, P.R. China; \\ 2. Department of First Chemotherapy, Affiliated Cancer Hospital of Guangxi Medical University, 71 Hedi Road, Nanning 530021, P. R. China; \\ 3. State Key Laboratory of Ophthalmology, Zhongshan Ophthalmic Center, Sun Yat-sen University, Guangzhou 510060, P. R. China; \\ 4. State Key Laboratory of Oncology in South China; Department of Pathology, Sun Yat-Sen University Cancer Center; Collaborative Innovation Center for \\ Cancer Medicine, Guangzhou 510060, P.R. China; \\ 5. University of Illinois at Chicago, Biological Science, Chicago, Illinois 60607, USA. \\ * These authors contributed equally to this paper.
}

$\square$ Corresponding authors: Qiuliang Wu, Department of Pathology, State Key Laboratory of Oncology in South China, Sun Yat-Sen University Cancer Center, Collaborative Innovation Center for Cancer Medicine, No. 651 Dongfeng Road East, Guangzhou 510060, P.R. China; Tel: +86- 20-87342270, E-mail: wuq1@sysucc.org.cn; Yucheng Wei, Department of Thoracic Surgery, Affiliated Hospital of Qingdao University, No. 16 Jiangsu Rd, Shinan, Qingdao 266000, P.R.China; Tel:+86-186-6197-1922, Email: weiyuchengchest@163.com.

(C) Ivyspring International Publisher. Reproduction is permitted for personal, noncommercial use, provided that the article is in whole, unmodified, and properly cited. See http://ivyspring.com/terms for terms and conditions.

Received: 2016.02.28; Accepted: 2016.04.26; Published: 2016.06.18

\begin{abstract}
Objective: Fatty acid desaturase 1 is a member of the fatty acid desaturase, which is related to a number of diseases. However, its role in cancers remains unclear. This study was to explore the clinical importance of FADS1 expression in non-small-cell lung cancer (NSCLC). Materials and Methods: Immunochemistry was used to evaluate FADS1 expressions in 216 paraffin-embedded specimens. The expression of FADSI was divided into high and low groups. The clinical and prognostic significance of FADSI expression was analyzed statistically by Kaplan-Meier estimate and Cox regression model. Results: FADS1 overexpressed in normal bronchial mucosa compared with non-small-cell lung cancer. Reduced FADS1 expression was associated with tumor size $(P=0.023)$ and histological grade $(P<0.0001)$. Patients with lower expression of FADS1 had shorter overall survival and disease free survival $(P=0.001$ and $P=0.002)$. Multivariate analysis showed FADS1 expression was an independent prognostic factor in NSCLC ( $P=0.011)$. Conclusion: Reduced expression of FADS1 suggests pessimistic prognosis for NSCLC patients. Further studies are warranted.
\end{abstract}

Key words: non-small-cell lung cancer (NSCLC), Fatty acid desaturase 1 (FADS1), immunohistochemistry (IHC).

\section{Introduction}

Lung cancer has ranked as the first cause of cancer related death in America and worldwide for several years. There are estimated to be 1.8 million new lung cancer cases every year, accounting for $13 \%$ of overall cancer incidence [1, 2]. Non-small cell lung cancer (NSCLC), including adenocarcinoma, squamous cell carcinoma, bronchoalveolar cell carcinoma, and large-cell carcinoma, accounts for about $85 \%$ of lung cancers [3]. To date, the overall 5 -year survival rate for NSCLC remains 15\% because of the lack of an effective clinical method for early diagnosis for patients with NSCLC.

Fatty acid desaturase 1 (FADS1) is a member of the fatty acid desaturase gene family [4]. Desaturase enzymes desaturate fatty acids by introducing double bonds between defined carbons of the fatty acyl chain. FADS1 and its homolog FADS2 are located in a gene cluster at 11q12-q13.1, a chromosomal region related to a variety of complex diseases, including asthma [5], atopy [6], osteoarthritis [7], and type 1 diabetes [8]. The well-known biological function of FADS1 is to delta-5 desaturate (D5D) linoleic acid or a-linolenic 
acid, acting as the rate limiting enzyme of long-chain polyunsaturated fatty acids (LC-PUFA) [9]. LC-PUFAs are precursors of eicosanoids and other similar mediators and hence are important participant of inflammatory processes [10]. However, the relationship of FADSs and cancer has not yet been documented.

The objective of this study was to investigate the expression of FADS1 in NSCLC and further explore its clinical significance. We detected the expression of FADS1 in a total of 216 samples of NSCLC patients by immunohistochemistry (IHC). Correlations of FADS1 expression with NSCLC clinicopathologic features and survival were also assessed.

\section{Materials and Methods}

\section{Clinical Samples}

216 patients were enrolled in the study, who were diagnosed with NSCLC between October 2000 and April 2007 at the Sun Yat-sen University Cancer Center (SYSUCC) and underwent NSCLC excision before radiation or chemotherapy. NSCLC tissues and adjacent nonmalignant tissues were sectioned and subjected to immunohistochemistry (IHC) staining. The histological grade and clinical stage were determined according to the seventh edition of the TNM classification of the International Union Against Cancer (UICC, 2009). The cases that fulfilled the following criteria were selected in this study: (1) newly diagnosed NSCLC without previous treatment; (2) histologically confirmed primary NSCLC; (3) no history of familial malignancy or other synchronous malignancy; (4) underwent a surgical resection including segmentectomy, lobectomy or pneumonectomy; (5) necessary clinical and follow-up data were available; (6) no recurrent NSCLC cancer. Patients were excluded if died from postoperative complications. The clinical data of patients was obtained from SYSUCC hospital records. This study was approved by the independent Institute research ethics committee of SYSUCC.

\section{IHC and evaluation}

IHC staining was used to visualize the expression of FADS1. Specific steps were conducted as previously described [11]. The specimens were firstly deparaffinized and rehydrated, followed by washing in PBS. Then the slides were boiled for 15 minutes in citric acid in a microwave oven to retrieve antigen. After slides being treated with 3\% hydrogen peroxide buffered in methanol, 1\% BSA was used to block non-specific binding. The sections were subsequently incubated with rabbit anti human polyclonal antibody against FADS1 (10627-1-AP, 1:1000 dilution; Proteintech) overnight at $4^{\circ} \mathrm{C}$.
Negative controls were prepared by skipping the primary antibodies. The sections were incubated with horseradish peroxidase at $37^{\circ} \mathrm{C}$ for 30 minutes after that, followed by incubated with 3,30-diaminobenzidine solution for visualization.

Two independent pathologists (Bei Gao and Shumei Yan) blinded to the clinicopathological information performed the immunoreactivity score (IRS) of FADS1 expression for 216 NSCLC specimens. The staining results were scored according to two criteria: (a) positive tumor cells percentage in the tumor tissue: $0(0 \%), 1$ (1\% to $10 \%), 2$ (11\% to $50 \%), 3$ (51\% to $75 \%)$, and 4 (76\% to $100 \%)$; and (b) intensity of staining: $0=$ absent; $1=$ weak; $2=$ intermediate and $3=$ strong. These two scores were multiplied and the IRS (range from 0 to 12) was obtained. The average IRS for each case by the two pathologists was assigned as the staining result. If the IRS difference between the two pathologists' results was greater than 3, the specimens were rescored. All 216 NSCLC patients were divided into two groups according to the median IRS scores and the IRS higher than 8 was considered as high expression.

\section{Statistical Analysis}

The statistical analysis was performed by the SPSS 17.0 software statistical software package. The correlation between FADS1 expression and clinicopathologic variables was evaluated using Pearson's $\chi^{2}$ test. Disease free survival (DFS) and overall survival (OS) curves were performed by the Kaplan-Meier survival plot and compared by the log-rank test. A Cox proportional hazard regression was used for univariate and multivariate survival analysis. A two-sided $\mathrm{P}<0.05$ was considered statistically significant.

\section{Results}

\section{Patients' characteristics}

One-hundred and fifty-five males and sixty-one females, aged from 30 to 79 years (median 59.0 years), were included in the study. The clinicopathological characteristics of the 216 patients were listed in Table 1.

\section{Expression of FADS1 in NSCLC}

Immunostaining of FADS1 in NSCLC tissues were shown as brown yellow granules in cytoplasm (Fig 1,2 and 3). The expression of FADS1 was divided into two subgroups: low FADS1 expression and high FADS1 expression as defined in the section of Materials and Methods. High expression of FADS1 was detected in $32.9 \%$ (71 of 216) NSCLC tissues, whereas low expression of FADS1 was account for $67.1 \%$ (145 of 216$)$ of the cases. 
Table 1. Correlation between FADS1 expression and clinicopathological variables of NSCLC cases.

\begin{tabular}{|c|c|c|c|c|}
\hline \multirow[t]{2}{*}{ Variables } & \multirow{2}{*}{$\begin{array}{l}\text { Cases } \\
(\mathrm{n}=216)\end{array}$} & \multicolumn{2}{|c|}{ FADS1 expression } & \multirow[t]{2}{*}{ P value } \\
\hline & & Low & High & \\
\hline Age (years) & & & & 0.161 \\
\hline$<60$ & 110 & $69(31.9)$ & $41(19.0)$ & \\
\hline$\geq 60$ & 106 & $76(35.2)$ & $30(13.9)$ & \\
\hline Gender & & & & 0.111 \\
\hline Male & 155 & $109(50.5)$ & $46(21.3)$ & \\
\hline Female & 61 & $36(16.7)$ & $25(11.6)$ & \\
\hline Tumor size(cm) & & & & $0.023^{*}$ \\
\hline$\leq 3.5$ & 110 & $66(30.6)$ & $44(20.4)$ & \\
\hline$>3.5$ & 106 & $79(36.6)$ & $27(12.5)$ & \\
\hline Tumor category & & & & 0.132 \\
\hline Adenocarcinoma(AC) & 121 & $74(34.3)$ & $47(21.8)$ & \\
\hline Squamous cancer(SC) & 78 & $60(27.8)$ & $18(8.3)$ & \\
\hline $\begin{array}{l}\text { Adenosquamous } \\
\text { carcinoma(A-SC) }\end{array}$ & 15 & $10(4.6)$ & $5(2.3)$ & \\
\hline Large cell carcinoma(LCC) & 2 & $1(0.5)$ & $1(0.5)$ & \\
\hline Histological grade & & & & $<0.0001^{*}$ \\
\hline Well differentiated (G1) & 31 & $16(7.4)$ & $15(6.9)$ & \\
\hline $\begin{array}{l}\text { Moderately differentiated } \\
\text { (G2) }\end{array}$ & 88 & $50(23.1)$ & $38(17.6)$ & \\
\hline Poorly differentiated (G3) & 97 & $79(36.6)$ & $18(8.3)$ & \\
\hline Tumor status $(\mathrm{T})$ & & & & 0.053 \\
\hline $\mathrm{T} 1$ & 41 & $23(10.6)$ & 18(8.3) & \\
\hline $\mathrm{T} 2$ & 147 & $98(45.4)$ & $49(22.7)$ & \\
\hline $\mathrm{T} 3$ & 20 & $16(7.4)$ & $4(1.9)$ & \\
\hline $\mathrm{T} 4$ & 8 & $8(3.7)$ & $0(0)$ & \\
\hline Nodal status (N) & & & & 0.346 \\
\hline N0 & 121 & $78(36.1)$ & 43(19.9) & \\
\hline $\mathrm{N}>0$ & 95 & $67(31.0)$ & $28(13.0)$ & \\
\hline TNM Staging & & & & 0.083 \\
\hline I & 94 & $56(25.9)$ & $38(17.6)$ & \\
\hline II & 58 & $44(20.4)$ & $14(6.5)$ & \\
\hline III & 63 & $45(20.8)$ & $18(8.3)$ & \\
\hline
\end{tabular}

\section{The correlations between FADS1 expression and NSCLC clinical characters}

The associations between clinicopathologic features and FADS1 expression are summarized in Table 1. FADS1 expression correlated closely with tumor size $(\mathrm{P}=0.023)$ and histological grade $(\mathrm{P}<0.0001)$. However, no statistical associations were observed between FADS1 expression and age, gender, tumor category, tumor status, nodal status and TNM classification $(\mathrm{P}=0.161,0.111,0.132,0.053,0.346$ and 0.083 respectively).

\section{FADS1 expression and survival analysis}

The association between FADS1 expression and OS in 216 NSCLC cases was analyzed by Kaplan-Meier methods. No patient was reported as lost to follow-up. 112 patients were deceased while 104 were alive at the end. The median observation time was 70.0 months (0-126 months). The estimated 5 -year DFS and OS rates for the entire cohort were $44.0 \%$ and $53.7 \%$, with median survival from diagnosis of 43.1 and 70.0 months, respectively.
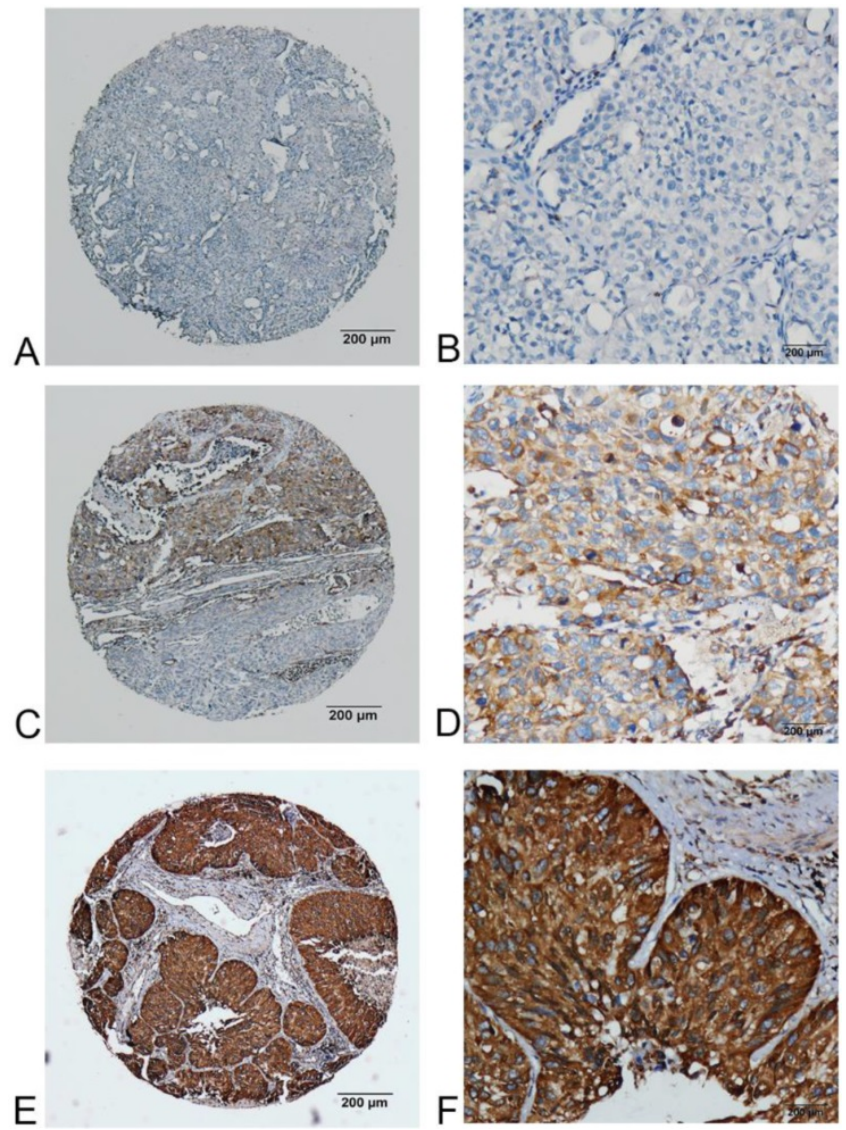

Figure 1. FADS1 expression in squamous carcinoma phenotype of NSCLC detected by IHC. (A, B) no or very low expression of FADSI protein in the cytoplasm of squamous carcinoma cells (magnification: A, ×40; B, ×200). (C, D) low expression level of FADSI protein in squamous carcinoma cells (magnification: C, $\times 40$; D, $\times 200$ ). $(E, F)$ high expression levels of FADS1 detected in squamous carcinoma cells (magnification: $E, \times 40 ; \mathrm{F}, \times 200$ ).

High FADS1 expression was associated with better prognosis in patients. Specifically, the mean OS for high FADS1 group is 93.4 months, whereas that for low FADS1 group is 68.1 months. ( $\mathrm{P}=0.001$, Fig. 4, Table 2). A parallel result was obtained for DFS (mean of 87.2 months versus 61.0 months, $\mathrm{P}=0.002$, Fig. 4 , Table 2). In the subgroup analysis, FADS1 expression could stratify the DFS/OS for T status, $\mathrm{N}$ status and histologic grade (table 2).

Univariate Cox's proportional hazard model showed the following factors correlated significantly with OS: histological grade, TNM Staging, nodal status and FADS1 expression (Table 3). When the above parameters were included in multivariate analysis, the model indicated tumor size, nodal status and FADS1 expression were independent factors that affected OS (Table 3). We also did the survival analysis based on DFS data. Univariate analysis showed that tumor size, histological grade, TNM Staging, nodal status and FADS1 expression correlated significantly with DFS (Table 4). Subsequent multivariate analysis showed that only nodal status and FADS1 expression were independent factors that affected DFS (Table 4). 

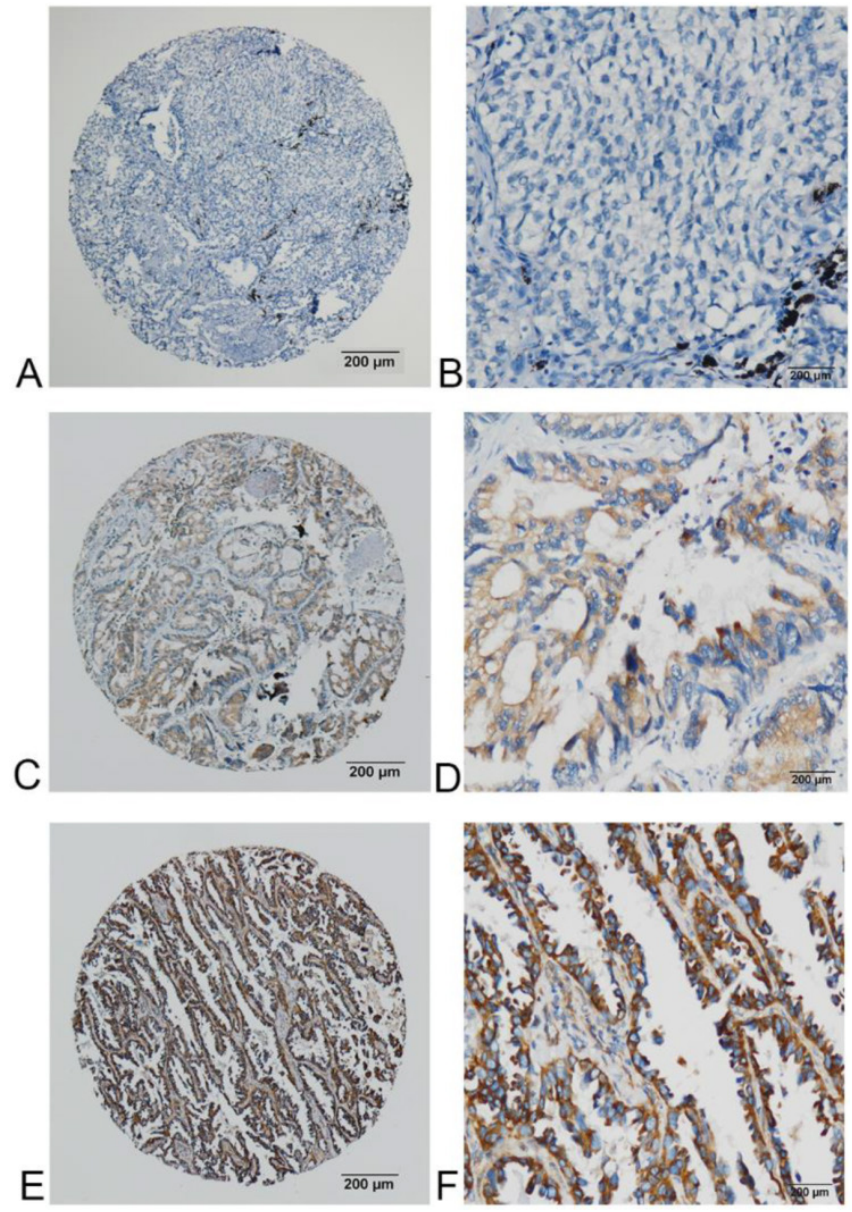

Figure 2. FADS1 expression in adenocarcinoma phenotype of NSCLC detected by IHC. (A, B) no or very low expression of FADS1 protein in the cytoplasm of adenocarcinoma cells (magnification: A, ×40; B, ×200). (C, D) low expression level of FADS1 protein in adenocarcinoma cells (magnification: $\mathrm{C}$, $\times 40 ; \mathrm{D}, \times 200)$. (E, F) high expression levels of FADS1 detected in adenocarcinoma cells (magnification: $E, \times 40 ; F, \times 200$ ).

Table 3. Univariate and multivariate analyses of overall survival of NSCLC patients.

\begin{tabular}{|c|c|c|c|c|c|c|}
\hline \multirow[t]{2}{*}{ Variables } & \multicolumn{3}{|c|}{ Univariate analyses } & \multicolumn{3}{|c|}{ Multivariate analyses } \\
\hline & $\mathrm{HR}$ & $(95 \% \mathrm{CI})$ & $\mathrm{p}$ value & HR & $(95 \% \mathrm{CI})$ & $\begin{array}{l}\mathrm{p} \\
\text { value }\end{array}$ \\
\hline $\begin{array}{l}\text { Age (years), }(<60 \\
\text { vs. } \geq 60)\end{array}$ & 1.069 & $0.739-1.546$ & 0.723 & & & \\
\hline $\begin{array}{l}\text { Gender (male vs. } \\
\text { female) }\end{array}$ & 1.040 & $0.691-1.566$ & 0.852 & & & \\
\hline $\begin{array}{l}\text { Tumor } \\
\text { size }(\mathrm{cm})(\leq 3.5 \text { vs. }> \\
3.5)\end{array}$ & 1.678 & $1.157-2.436$ & $0.006^{*}$ & 1.620 & $1.006-2.461$ & $\begin{array}{l}0.024 \\
*\end{array}$ \\
\hline $\begin{array}{l}\text { Tumor } \\
\text { category(AC/SC/A } \\
\text {-SC/LCC) }\end{array}$ & 1.031 & $0.781-1.362$ & 0.829 & & & \\
\hline $\begin{array}{l}\text { Histological grade, } \\
\text { (G3/G2/G1) }\end{array}$ & 1.393 & $1.055-1.839$ & $0.02^{*}$ & 0.995 & $0.695-1.312$ & 0.776 \\
\hline $\begin{array}{l}\text { TNM Staging } \\
\text { (I/II/III) }\end{array}$ & 1.934 & $1.553-2.409$ & $\begin{array}{l}< \\
0.001^{*}\end{array}$ & 1.087 & $0.724-1.631$ & 0.687 \\
\hline $\begin{array}{l}\text { Nodal status } \\
(\mathrm{N}>0 / \mathrm{N} 0)\end{array}$ & 3.363 & $2.283-4.954$ & $\begin{array}{l}< \\
0.001^{*}\end{array}$ & 2.917 & $1.466-5.802$ & $\begin{array}{l}0.002 \\
*\end{array}$ \\
\hline $\begin{array}{l}\text { FADS1 expression, } \\
\text { (High/Low) }\end{array}$ & 0.473 & $0.303-0.739$ & $0.001^{*}$ & 0.489 & $0.307-0.779$ & $\begin{array}{l}0.003 \\
*\end{array}$ \\
\hline
\end{tabular}

Table 2. FADSI expression in NSCLC patients by Kaplan-Meier survival analysis (log-rank test).

\begin{tabular}{|c|c|c|c|c|c|c|c|}
\hline \multirow[t]{2}{*}{ Variable } & \multirow[t]{2}{*}{ Case } & \multicolumn{3}{|c|}{ DFS (months) } & \multicolumn{3}{|c|}{ OS (months) } \\
\hline & & Mean & Median & P-value & Mean & Median & P-value \\
\hline \multicolumn{8}{|l|}{ Total } \\
\hline Low expression & 145 & 61.0 & 42.8 & 0.002 & 68.1 & 55.4 & 0.001 \\
\hline High expression & 71 & 87.2 & NR & & 93.4 & NR & \\
\hline \multicolumn{8}{|l|}{$\mathrm{T}$ categories } \\
\hline \multicolumn{8}{|l|}{$\mathrm{T} 1-2$} \\
\hline Low expression & 121 & 64.0 & 43.1 & 0.017 & 72.0 & 65.1 & 0.010 \\
\hline High expression & 67 & 84.7 & NR & & 91.4 & NR & \\
\hline \multicolumn{8}{|l|}{ T3-4 } \\
\hline Low expression & 24 & 60.5 & 27.0 & 0.011 & 65.1 & 38.0 & 0.010 \\
\hline High expression & 4 & 75.6 & NR & & 82.3 & NR & \\
\hline \multicolumn{8}{|l|}{$\mathrm{N}$ categories } \\
\hline \multicolumn{8}{|l|}{$\mathrm{N}=0$} \\
\hline Low expression & 78 & 80.7 & NR & 0.008 & 85.8 & NR & 0.007 \\
\hline High expression & 43 & 107.9 & NR & & 110.4 & NR & \\
\hline \multicolumn{8}{|l|}{$\mathrm{N}=1 / 2 / 3$} \\
\hline Low expression & 67 & 36.7 & 20.0 & 0.195 & 46.6 & 29.0 & 0.059 \\
\hline High expression & 28 & 56.1 & 21.9 & & 65.9 & 52.9 & \\
\hline \multicolumn{8}{|l|}{ Histologic grade } \\
\hline \multicolumn{8}{|l|}{ G1 } \\
\hline Low expression & 16 & 73.3 & 101.5 & 0.217 & 75.1 & 101.5 & 0.219 \\
\hline High expression & 15 & 98.8 & NR & & 101.3 & NR & \\
\hline G2-3 & & & & & & & \\
\hline Low expression & 129 & 59.2 & 31.7 & 0.009 & 67.0 & 51.6 & 0.003 \\
\hline High expression & 56 & 83.3 & NR & & 90.7 & NR & \\
\hline
\end{tabular}

Table 4. Univariate and multivariate analyses of disease free survival of NSCLC patients.

\begin{tabular}{|c|c|c|c|c|c|c|}
\hline \multirow[t]{2}{*}{ Variables } & \multicolumn{3}{|c|}{ Univariate analyses } & \multicolumn{3}{|c|}{ Multivariate analyses } \\
\hline & $\overline{\mathrm{HR}}$ & $(95 \% \mathrm{CI})$ & $\begin{array}{l}\mathrm{p} \\
\text { value }\end{array}$ & $\mathrm{HR}$ & $(95 \% \mathrm{CI})$ & $\begin{array}{l}\mathrm{p} \\
\text { value }\end{array}$ \\
\hline Age (years), $(<60$ vs. $\geq 60)$ & $\begin{array}{l}0.98 \\
8\end{array}$ & $\begin{array}{l}0.683-1.42 \\
8\end{array}$ & 0.947 & & & \\
\hline Gender (male vs. female) & $\begin{array}{l}1.08 \\
4\end{array}$ & $\begin{array}{l}0.720-1.63 \\
3\end{array}$ & 0.698 & & & \\
\hline $\begin{array}{l}\text { Tumor size }(\mathrm{cm})(\leq 3.5 \mathrm{vs.}> \\
3.5)\end{array}$ & $\begin{array}{l}1.62 \\
5\end{array}$ & $\begin{array}{l}1.120-2.35 \\
8\end{array}$ & $\begin{array}{l}0.011 \\
*\end{array}$ & $\begin{array}{l}1.43 \\
6\end{array}$ & $\begin{array}{l}0.952-2.16 \\
8\end{array}$ & 0.085 \\
\hline $\begin{array}{l}\text { Tumor } \\
\text { category(AC/SC/A-SC/LC } \\
\text { C) }\end{array}$ & $\begin{array}{l}1.03 \\
3\end{array}$ & $\begin{array}{l}0.783-1.36 \\
3\end{array}$ & 0.819 & & & \\
\hline $\begin{array}{l}\text { Histological grade, } \\
\text { (G3/G2/G1) }\end{array}$ & $\begin{array}{l}1.40 \\
0\end{array}$ & $\begin{array}{l}1.065-1.84 \\
1\end{array}$ & $\begin{array}{l}0.016 \\
*\end{array}$ & $\begin{array}{l}0.99 \\
2\end{array}$ & $\begin{array}{l}0.727-1.35 \\
3\end{array}$ & 0.959 \\
\hline TNM Staging (I/II/III) & $\begin{array}{l}1.96 \\
4\end{array}$ & $\begin{array}{l}1.576-2.44 \\
9\end{array}$ & $\begin{array}{l}< \\
0.001 \\
*\end{array}$ & $\begin{array}{l}1.13 \\
2\end{array}$ & $\begin{array}{l}0.752-1.70 \\
4\end{array}$ & 0.551 \\
\hline Nodal status $(\mathrm{N}>0 / \mathrm{N} 0)$ & $\begin{array}{l}3.42 \\
9\end{array}$ & $\begin{array}{l}2.324-5.06 \\
0\end{array}$ & $\begin{array}{l}< \\
0.001 \\
*\end{array}$ & $\begin{array}{l}2.72 \\
2\end{array}$ & $\begin{array}{l}1.360-5.44 \\
7\end{array}$ & $\begin{array}{l}0.005 \\
*\end{array}$ \\
\hline $\begin{array}{l}\text { FADS1 expression, } \\
\text { (High/Low) }\end{array}$ & $\begin{array}{l}0.49 \\
8\end{array}$ & $\begin{array}{l}0.319-0.77 \\
8\end{array}$ & $\begin{array}{l}0.002 \\
*\end{array}$ & $\begin{array}{l}0.54 \\
7\end{array}$ & $\begin{array}{l}0.343-0.87 \\
2\end{array}$ & $\begin{array}{l}0.011 \\
*\end{array}$ \\
\hline
\end{tabular}



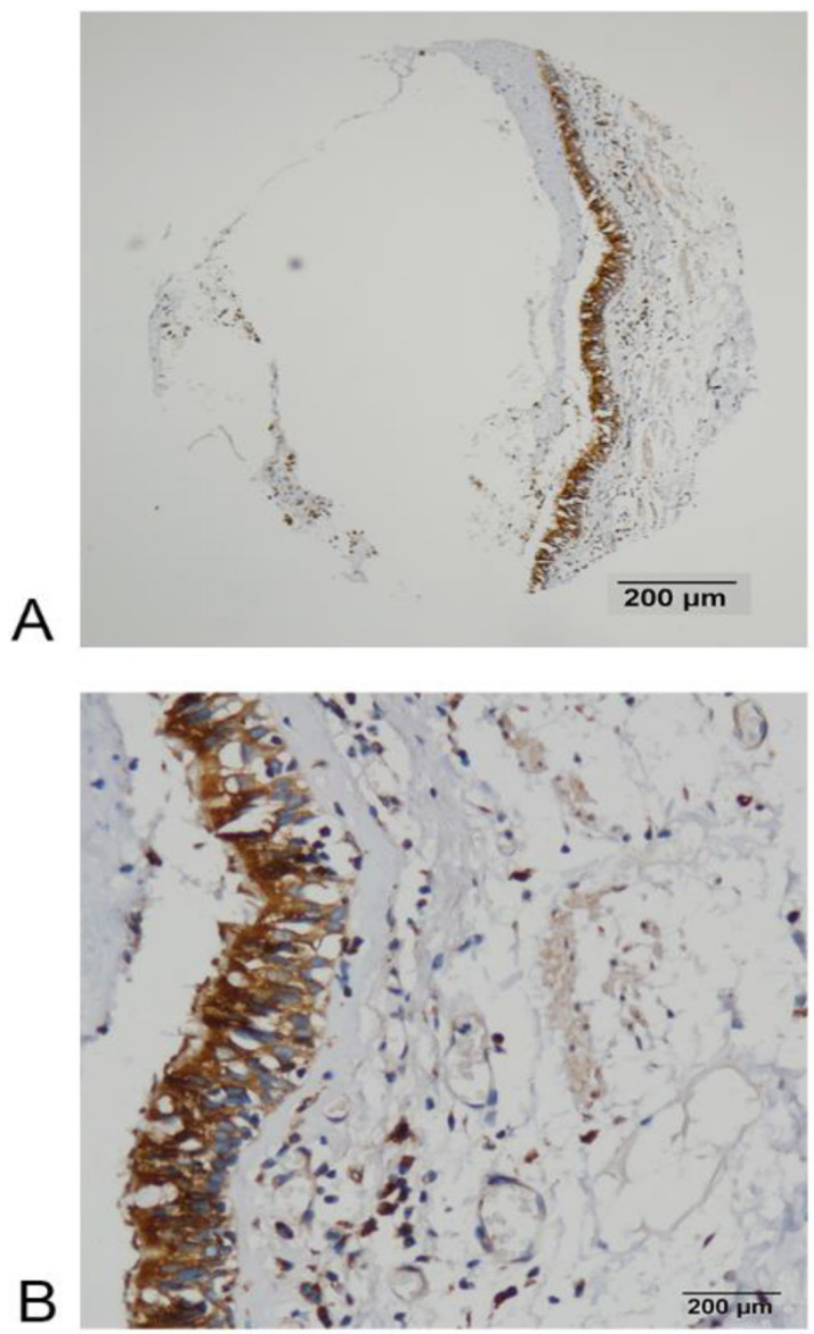

Figure 3. FADS1 expression in normal bronchial mucosa detected by IHC. (A, B) High expression of FADS1 protein in normal bronchial mucosa (magnification: A, ×40; B, ×200).

\section{Discussion}

FADS1 was successfully cloned in 1999 for the first time and its biological role is to delta- 5 desaturate (D5D) linoleic acid or a-linolenic acid, forming LC-PUFA) [12]. LC-PUFAs are main precursors for eicosanoids and docosanoids synthesis and hence can greatly affect inflammatory processes [13]. FADS1 cluster showed strong association with the n- 6 and n-3 fatty acids in an analysis of single nucleotide polymorphisms (SNPs) of the FADS1 gene cluster in 727 participants from Erfurt Center [14]. Subsequently, series of studies are focused on the role of FADS1 polymorphism in fatty acid metabolism and a variety of diseases, such as cardiovascular disease and essential fatty acids metabolism in women during pregnancy and during lactation [15-17]. However, the
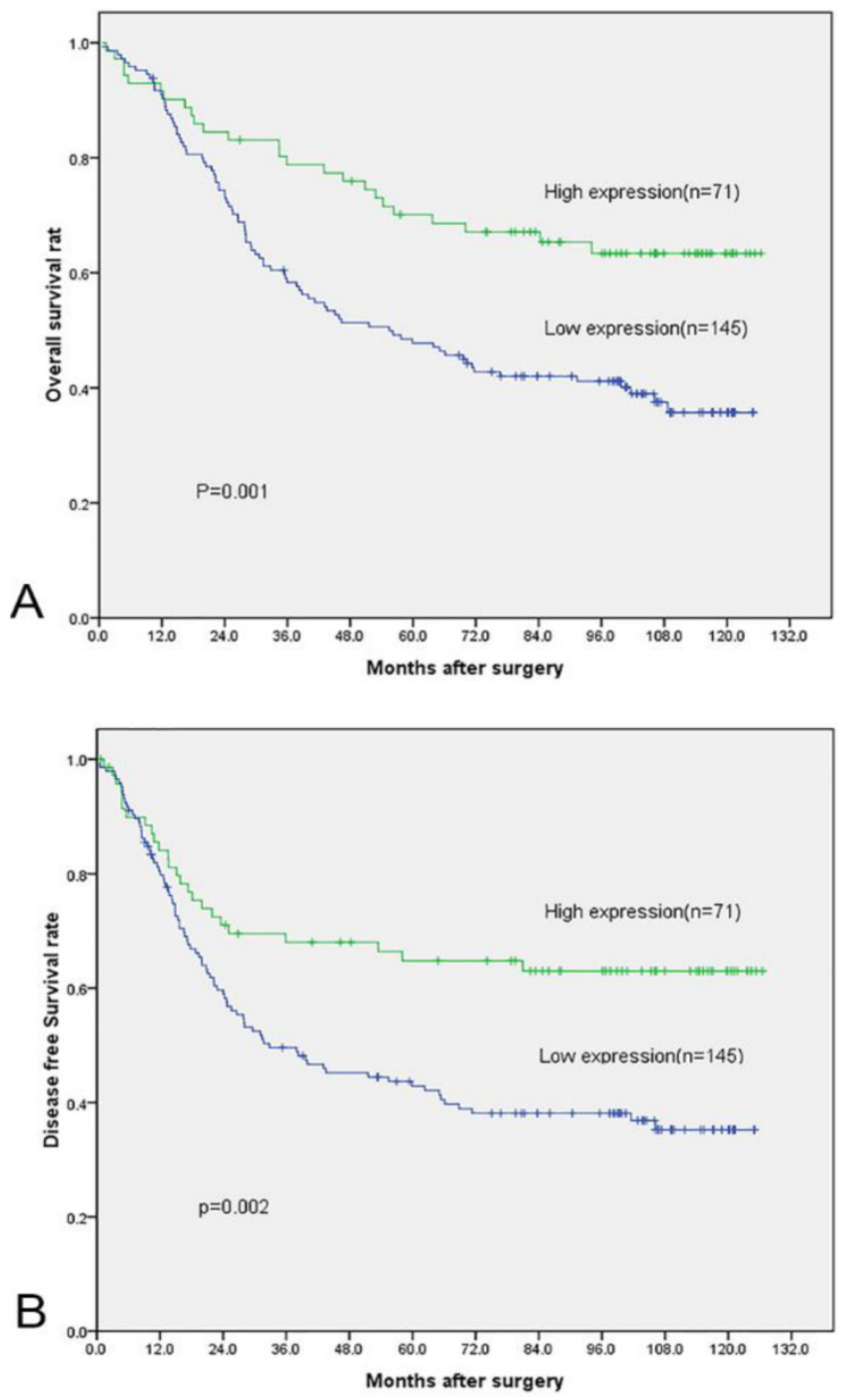

Figure 4. Overall Survival and Disease Free Survival curves of 216 NSCLC patients according to their FADS1 expression status. (A) OS curves: two groups of NSCLC patients with different levels of FADSI expression. (B) DFS curves: two groups of NSCLC patients with different levels of FADS1 expression.

role of FADS1 in cancer development and prognosis are scarcely reported.

In this study, we, for the first time, reported that FADS1 might play a role in cancer development and prognosis. Our data supported that reduced expression of FADS1 was associated with larger size of tumors and poorer differentiation, indicating that it's reduced expression might provide some developing advantages for NSCLC. Based on existing documents about FADS1, we hypothesize some possible mechanisms by which FADS1 exerts its effects. First of all, it is very likely that FADS1 affects NSCLC tumorigenesis through inflammation since newly identified catalytic products E-series resolvins and D-series resolvins of FADS1 are strong anti-inflammatory molecules $[18,19]$. To the best of our knowledge, tumorigenesis is a complex process in 
which chronic inflammation could facilitate it as a common promotor, which has been proved by previous studies $[20,21]$. So, it's plausible that FADS1's anti-inflammatory products possess anti-cancer effects.

In addition, it has been broadcasted that FADS1's polymorphism act as an important factor contributing to the variability in PUFA levels in serum phospholipids and erythrocyte membranes [22]. Lipoproteins are essential receptors or transmitters of different normal and pathological physiological events, such as cell apoptosis, autophagy, growth and cell cycle [23, 24]. To some extent, tumor is defined as a disease of unregulated metabolism. The famous Warburg Effect theory is still of great interest to scientists after four decades [25]. We hypothesize that FADS1 might affect tumorigenesis of NSCLC through lipid metabolism. However, the rationale behind it is still elusive.

Most importantly, the cumulative 5-year OS and DFS rates of patients with high FADS1 expression were higher than those with low FADS1 expression (i.e., patients with high FADS1 expression have a better prognosis than those with low or absent FADS1 expression). Kaplan-Meier analysis and Cox multivariate analysis revealed that FADS1 expression is an independent prognostic factor for NSCLC. These results collectively indicate that FADS1 has the potential to be useful biomarker of NSCLC early diagnosis and prognosis prediction. Clinical data demonstrated that early detection could significantly improve NSCLC survival [26]. Great advances have been made for early detection of lung cancer via the development of computer tomography (CT) screening of nonsymptomatic individuals [27]. However, because of the relatively low specificity of CT screening and expensive costs, there is still an urgent need for better diagnosis system of NSCLC patients with precision and economic efficiency. Thus, various studies of biomarkers for NSCLC, such as carcinoembryonic antigen, squamous cell carcinoma antigen, cytokeratin-19 fragment, and neuron-specific enolase, have been identified and exhibit unprecedented potential [28, 29]. Based on our data, we sincerely hope that FADS1, in the future, could benefit the establishment of a more accurate and comprehensive diagnosis and treatment network, leading to improved clinical outcomes.

In conclusion, our study showed that the reduced expression level of FADS1 is correlated to the larger tumor size and the poorer tumor differentiation. Moreover, FADS1 expression is an independent prognostic factor for NSCLC and lower expression of FADS1 predict worse prognosis of NSCLC. However, the detailed mechanism by which
FADS1 regulates tumorigenesis requires further studies.

\section{Competing Interests}

The authors have declared that no competing interest exists.

\section{References}

1. Torre LA, Bray F, Siegel RL, Ferlay J, Lortet-Tieulent J, Jemal A. Global cancer statistics, 2012. CA: a cancer journal for clinicians. 2015; 65: 87-108.

2. Siegel R, Naishadham D, Jemal A. Cancer statistics, 2013. CA: a cancer journal for clinicians. 2013; 63: 11-30.

3. Houghton AM. Mechanistic links between COPD and lung cancer. Nature reviews Cancer. 2013; 13: 233-45.

4. Ralston JC, Matravadia S, Gaudio N, Holloway GP, Mutch DM. Polyunsaturated fatty acid regulation of adipocyte FADS1 and FADS2 expression and function. Obesity. 2015; 23: 725-8.

5. Huang JL, Gao PS, Mathias RA, Yao TC, Chen LC, Kuo ML, et al. Sequence variants of the gene encoding chemoattractant receptor expressed on Th2 cells (CRTH2) are associated with asthma and differentially influence mRNA stability. Human molecular genetics. 2004; 13: 2691-7.

6. Stafford AN, Rider SH, Hopkin JM, Cookson WO, Monaco AP. A 2.8 Mb YAC contig in 11q12-q13 localizes candidate genes for atopy: Fc epsilon RI beta and CD20. Human molecular genetics. 1994; 3: 779-85.

7. Chapman K, Mustafa Z, Irven C, Carr AJ, Clipsham K, Smith A, et al. Osteoarthritis-susceptibility locus on chromosome 11q, detected by linkage. American journal of human genetics. 1999; 65: 167-74.

8. Nakagawa Y, Kawaguchi Y, Twells RC, Muxworthy C, Hunter KM, Wilson A, et al. Fine mapping of the diabetes-susceptibility locus, IDDM4, on chromosome 11q13. American journal of human genetics. 1998; 63: 547-56.

9. Glaser C, Heinrich J, Koletzko B. Role of FADS1 and FADS2 polymorphisms in polyunsaturated fatty acid metabolism. Metabolism: clinical and experimental. 2010; 59: 993-9.

10. Calder PC. Polyunsaturated fatty acids, inflammatory processes and inflammatory bowel diseases. Molecular nutrition \& food research. 2008; 52: 885-97.

11. Li XH, He F, Yan SM, Li Y, Cao Y, Huang CY, et al. Increased expression of stomatin-like protein 2 (STOML2) predicts decreased survival in gastric adenocarcinoma: a retrospective study. Medical oncology. 2014; 31: 763.

12. Cho HP, Nakamura M, Clarke SD. Cloning, expression, and fatty acid regulation of the human delta-5 desaturase. The Journal of biological chemistry. 1999; 274: 37335-9.

13. Serhan $\mathrm{CN}$. Novel eicosanoid and docosanoid mediators: resolvins, docosatrienes, and neuroprotectins. Current opinion in clinical nutrition and metabolic care. 2005: 8: 115-21.

14. Schaeffer L, Gohlke H, Muller M, Heid IM, Palmer LJ, Kompauer I, et al. Common genetic variants of the FADS1 FADS2 gene cluster and their reconstructed haplotypes are associated with the fatty acid composition in phospholipids. Human molecular genetics. 2006; 15: 1745-56.

15. Malerba G, Schaeffer L, Xumerle L, Klopp N, Trabetti E, Biscuola M, et al. SNPs of the FADS gene cluster are associated with polyunsaturated fatty acids in a cohort of patients with cardiovascular disease. Lipids. 2008; 43: 289-99.

16. Xie L, Innis SM. Genetic variants of the FADS1 FADS2 gene cluster are associated with altered (n-6) and (n-3) essential fatty acids in plasma and erythrocyte phospholipids in women during pregnancy and in breast milk during lactation. The Journal of nutrition. 2008; 138: 2222-8.

17. Lattka E, Illig T, Koletzko B, Heinrich J. Genetic variants of the FADS1 FADS2 gene cluster as related to essential fatty acid metabolism. Current opinion in lipidology. 2010; 21: 64-9.

18. Funahashi H, Satake M, Hasan S, Sawai H, Newman RA, Reber HA, et al. Opposing effects of $n-6$ and $n-3$ polyunsaturated fatty acids on pancreatic cancer growth. Pancreas. 2008; 36: 353-62.

19. Schmitz G, Ecker J. The opposing effects of n-3 and n-6 fatty acids. Progress in lipid research. 2008; 47: 147-55.

20. De Lerma Barbaro A, Perletti G, Bonapace IM, Monti E. Inflammatory cues acting on the adult intestinal stem cells and the early onset of cancer (review). International journal of oncology. 2014; 45: 959-68.

21. Balkwill F, Charles KA, Mantovani A. Smoldering and polarized inflammation in the initiation and promotion of malignant disease. Cancer cell. 2005; 7: 211-7.

22. Rzehak P, Heinrich J, Klopp N, Schaeffer L, Hoff S, Wolfram G, et al. Evidence for an association between genetic variants of the fatty acid desaturase 1 fatty acid desaturase 2 (FADS1 FADS2) gene cluster and the fatty acid composition of erythrocyte membranes. The British journal of nutrition. 2009; 101: 20-6.

23. Leaver HA, Rizzo MT, Whittle IR. Glioma cell death: cell-cell interactions and signalling networks. Molecular neurobiology. 2010; 42: 89-96.

24. Wyllie AH. "Where, $\mathrm{O}$ death, is thy sting?" A brief review of apoptosis biology. Molecular neurobiology. 2010; 42: 4-9. 
25. Xu XD, Shao SX, Jiang HP, Cao YW, Wang YH, Yang XC, et al. Warburg effect or reverse Warburg effect? A review of cancer metabolism. Oncology research and treatment. 2015; 38: 117-22.

26. International Early Lung Cancer Action Program I, Henschke CI, Yankelevitz DF, Libby DM, Pasmantier MW, Smith JP, et al. Survival of patients with stage I lung cancer detected on CT screening. The New England journal of medicine. 2006; 355: $1763-71$

27. National Lung Screening Trial Research T, Aberle DR, Adams AM, Berg CD, Black WC, Clapp JD, et al. Reduced lung-cancer mortality with low-dose computed tomographic screening. The New England journal of medicine. 2011; 365: 395-409.

28. Yu D, Du K, Liu T, Chen G. Prognostic value of tumor markers, NSE, CA125 and SCC, in operable NSCLC Patients. International journal of molecular sciences. 2013; 14: 11145-56

29. Ma S, Shen L, Qian N, Chen K. The prognostic values of CA125, CA19.9, NSE, AND SCC for stage I NSCLC are limited. Cancer biomarkers : section A of Disease markers. 2011; 10: 155-62. 